JURNAL SOSIAL-EKONOMI PERTANIAN

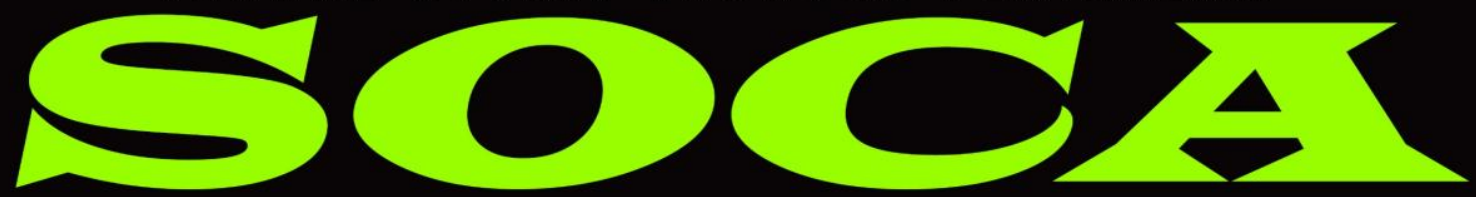

JOURNAL ON SOCIAL ECONOMICS OF AGRICULTURE

Vol.12 No.2 31 Desember 2018

e-ISSN: $2615-6628$

p-ISSN: $1411-7176$

\title{
ANALISIS RISIKO SUPPLY CHAIN PADA PT. PERIKANAN NUSANTARA (PERSERO) CABANG BENOA BALI
}

\author{
Fitri Puji Lestari, Ratna Komala Dewi dan I Ketut Suamba \\ Program Studi Agribisnis, Fakultas pertanian, Universitas Udayana \\ e-mail: fitri.puji2906@gmail.com,ratnadewi61@ymail.com dan suamba_unud@yahoo.co.id \\ HP: $085655343498,08123980542,08123993331$
}

\begin{abstract}
ABSTRAK
Kompleksitas jaringan supply chain yang melibatkan banyak pihak dan banyaknya ketidakpastian yang terjadi secara mendadak menjadi tantangan dalam pengelolaan supply chain perusahaan. Kondisi tersebut rentan terjadinya suatu risiko yang berdampak pada proses bisnis perusahaan. PT. Perikanan Nusantara (Persero) Cabang Benoa Bali merupakan salah satu perusahaan Badan Usaha Milik Negara (BUMN) yang bergerak dibidang penangkapan, pengolahan dan penyimpanan perikanan tangkap untuk di ekspor keluar negeri maupun dijual dalam negeri. Pengidentifikasian risiko melalui pemetaan Supply Chain Operations Reference (SCOR) diperoleh 21 risk event dan 51 risk agent yang tersebar pada acitivity plan, source, make, deliver, dan return. Risiko-risiko yang telah teridentifikasi dianalisis menggunakan metode Failure Mode and Effect Analysis (FMEA). Risiko yang tertinggi masuk pada kategori Intoreable dengan nilai RPN tertinggi yaitu 441, dan risiko yang terendah masuk pada kategori Broadly Acceptable dengan nilai RPN terendah yaitu 8. Terdapat delapan rencana mitigasi untuk meminimalisir risiko di PT. Perikanan Nusantara (Persero) Cabang Benoa Bali yaitu: (1) pelatihan kedisiplinan dalam bekerja, top manager lebih ketat monitoring pekerjaan, dan memberikan reward and punishment, (2) mempengaruhi atau membujuk customer lain untuk membeli ikan lebih banyak, memberikan penalti, dan memperjelas tentang PO, (3) melakukan analisa min max stock, (4) evaluasi ulang perencanaan sumberdaya manusia, (5) meeting pengusulan alur prosedur terbaik, (6) menyamakan timbangan dan memperkecil toleransi penyusutan, (7) memperhitungkan penambahan aset, (8) perekrutan sumberdaya manusia baru dan pelatihan terhadap karyawan baru. Saran yang diberikan oleh peneliti antara lain yaitu perusahaan perlu melakukan penilaian risiko secara berkala dan berkelanjutan agar dapat melakukan mitigasi untuk meminimalisir kerugian jika terjadi risiko yang berakibat negatif pada perusahaan.
\end{abstract}

Kata Kunci: Risiko, Supply Chain, Failure Mode and Effect Analysis 


\title{
SUPPLY CHAIN RISK ANALYSIS ON PT. PERIKANAN NUSANTARA (PERSERO) BRANCH BENOA BALI
}

\begin{abstract}
The complexity of supply chain that involves many parties and incidental uncertainties is quite a challenge in managing a company's supply chain. This condition is fragile to risk that may affect the company's business process. PT. Perikanan Nusantara (Persero) that is a State-Owned Enterprise that focuses in fishing as well as its processing and storing, either to be exported or sold domestically. Risk identification through Supply Chain Operations Reference (SCOR) mapping obtained 21 risk events and 51 risk agents spread throughout plan, source, make, deliver, and return activities. The identified risks were analyzed using Failure Mode and Effect Analysis (FMEA) method. The highest risk was categorized into Intolerable category with the highest RPN value at 441, and the lowest risk was categorized into Broadly Acceptable category with the lowest RPN value of 8 . There were eight mitigation plans to minimize risks at the Benoa Bali Branch Office of PT. Perikanan Nusantara (Persero), they were: (1) Working discipline training, top managers monitor performance tighter, and provide reward and punishment, (2) Lobbying other customers to buy more fish, imposing sanctions, and making PO clear, (3) Conducting min max stock analysis, (4) $\mathrm{Re}$ evaluating human resources plans, (5) Meeting for best procedure flow proposal, (6) Synchronizing scales and minimizing depreciation tolerance, (7)Considering asset adding, (8) Recruiting new human resources and training new employees. The researcher recommends the company to perform risk assessment regularly and continuously in order to conduct mitigation to minimize loss if the risk is negative for the company.
\end{abstract}

Keywords: Risk, Supply Chain, Failure Mode and Effect Analysis

\section{PENDAHULUAN}

Persaingan dunia bisnis saat ini sangat ketat, sehingga perusahaan dituntut untuk memiliki strategi yang tepat agar dapat bertahan dalam persaingan bisnis. Strategi tersebut dapat dilakukan dengan mengelola supply chain perusahaan dengan tepat. Supply chain sudah menjadi kunci penting dalam daya saing dan tingkat keefektifan perusahaan (Womack and Jones, 2005, dalam Sanjoyo, 2016). Perusahaan yang dapat menjalankan kegiatan supply chain akan mendapatkan keuntungan tidak hanya jangka pendek, bahkan juga jangka panjang seperti kemungkinan peningkatan profit dari adanya kerjasama yang berkepanjangan dengan

https://ojs.unud.ac.id/index.php/soca berbagai pihak, perluasan pangsa pasar, dan kepuasan konsumen. Efektif tidaknya pengelolaan supply chain suatu perusahaan menjadi kunci apakah suatu perusahaan akan kompetitif di pasar (Pujawan et al., 2007). Pengelolaan supply chain perusahaan yang semakin efektif maka perusahaan akan kompetitif begitu pula sebaliknya. Sukses tidaknya suatu supply chain tidak akan lepas dari risiko-risiko yang melekat pada setiap aktivitasnya (Sanjoyo, 2016). Beberapa contoh risiko supply chain antara lain kekurangan bahan baku, kegagalan pemasok, meningkatnya harga bahan baku, kerusakan mesin, permintaan yang tidak pasti, peramalan yang tidak akurat, perubahan pesanan, dan kegagalan transportasi. Potensi risiko- 
risiko tersebut bisa terjadi, dan bila benar-benar terjadi tentu akan berdampak pada kinerja supply chain management perusahaan. Mengingat pentingnya supply chain setiap manajer organiasi perusahaan harus mampu melakukan perencanaan, pelaksanaan, pengendalian, dan manajemen risiko (Zaroni, 2015).

PT. Perikanan Nusantara yang terletak di Pelabuhan Benoa, Denpasar merupakan salah satu perusahaan milik Badan Usaha Milik Negara (BUMN). Penjualan di PT. Perikanan Nusantara pada tahun 2015 sampai dengan tahun 2017 mengalami fluktuasi. Penjualan mengalami peningkatan yang signifikan terjadi pada tahun 2016 ke tahun 2017, dimana dalam penjualan ikan whole fresh mengalami kenaikan 58,2\%, whole frozen mengalami kenaikan 140,2\%, dan ikan lainnya mengalami kenaikan 13,9\%. Berdasarkan jumlah penjualan yang mengalami peningkatan di tahun 2017, PT. Perikanan Nusantara ingin mempertahankan dan menjaga biaya produksi agar menghasilkan profit yang lebih besar setiap tahunnya. Melalui pembuatan kajian risiko rantai pasok, diharapkan dapat dijadikan dasar pertimbangan oleh perusahaan dalam menjalankan proses bisnisnya, sehingga perusahaan dapat meminimalisir peluang dan dampak risiko yang berpotensi menggagalkan strategi maupun tujuan perusahaan. Berdasarkan hal tersebut maka pada penelitian ini dilakukan tentang penerapan supply chain risk management (SCRM) di PT. Perikanan Nusantara untuk mengidentifikasi risiko yang mungkin terjadi dalam aktivitas supply chain perusahaan, melakukan perangkingan risiko, dan menentukan rencana mitigasi risiko.

\section{METODE PENELITIAN}

Penelitian ini adalah penelitian deskriptif kualitatif. Lokasi penelitian ini dilakukan di PT. Perikanan Nusantara (Persero) Cabang Benoa Bali yang dilaksanakan pada bulan Mei sampai dengan Oktober 2018. Jenis data yang digunakan adalah data kuantitatif dan data kualitatif yang bersumber dari data primer dan data sekunder. Data primer dalam penelitian ini adalah data yang diperoleh peneliti dari hasil wawancara dan brainstorming secara langsung dengan informan penelitian. Data sekunder dalam penelitian ini adalah berupa visi, misi, struktur organisasi, dokumen perusahaan, serta catatan-catatan yang terkait dengan supply chain PT. Perikanan Nusantara (Persero) Cabang Benoa Bali. Metode pengumpulan data yang akan dilakukan dalam penelitian ini adalah pengamatan, wawancara, brainstorming, dan studi pustaka.

Informan penelitian adalah orang yang dimanfaatkan untuk memberikan informasi tentang situasi dan kondisi latar penelitian (Moleong, 2009). Pemilihan informan pada penelitian ini dilakukan dengan cara purposive yaitu tujuh orang informan yang dipilih secara sengaja yang terdiri atas cold storage supervisior, partnership supervisior, fish collecting supervisior, catching supervisior, fish processing supervisior, quality control supervisior, dan marketing supervisior. Analisis data dalam penelitian ini diuraikan sebagai berikut.

1. Untuk mengetahui risiko-risiko yang mungkin terjadi terdapat dua langkah yang dilakukan, yaitu: (1) Memetakan aktivitas supply chain perusahaan dengan Supply Chain Operation Reference (SCOR) yang dinilai dari kerangka plan, make, 
source, deliver, dan return yang telah disesuaikan dengan batasan penelitian. (2) Melakukan wawancara dan brainstorming untuk mengidentifikasi risk event dan risk agent.

2. Untuk mengetahui ranking risiko terdapat tiga langkah yang dilakukan, yaitu: (1) Mengukur risiko dengan metode FMEA, dimana terdapat tiga faktor yang diperhitungkan yaitu severity (S), occurance (O), dan detection (D) dengan skala 1-10. (2) Meranking pembobotan nilai Risk Priority Number (RPN) dengan skala 1-1000 yang didapatkan dari perkalian tiga faktor tersebut, dimana dirumuskan dengan RPN = Severity $\mathrm{x}$ Occurance x Detection. (3) Memetakan level risiko menggunakan menggunakan peta level risiko FMEA.
3. Untuk membuat rencana mitigasi risiko, hal yang dilakukan adalah merumuskan mitigasi risiko sesuai dengan yang dipaparkan AS/NZS:2004.

\section{HASIL DAN PEMBAHASAN}

\section{Pemetaan Aktivitas Supply Chain PT. Perikanan Nusantara (Persero) Cabang Benoa Bali}

Aktivitas pada perusahaan ini terdapat tiga aliran supply chain yaitu aliran material, finansial, dan informasi. Aliran material merupakan aliran barang atau produk yang mengalir dari hulu ke hilir. Aliran finansial merupakan aliran uang yang biasanya mengalir dari hilir ke hulu. Aliran yang terakhir yaitu aliran informasi yang bisa mengalir dari hulu ke hilir maupun sebaliknya. Peta aktivitas supply chain PT. Perikanan Nusantara dijabarkan pada Gambar 1.

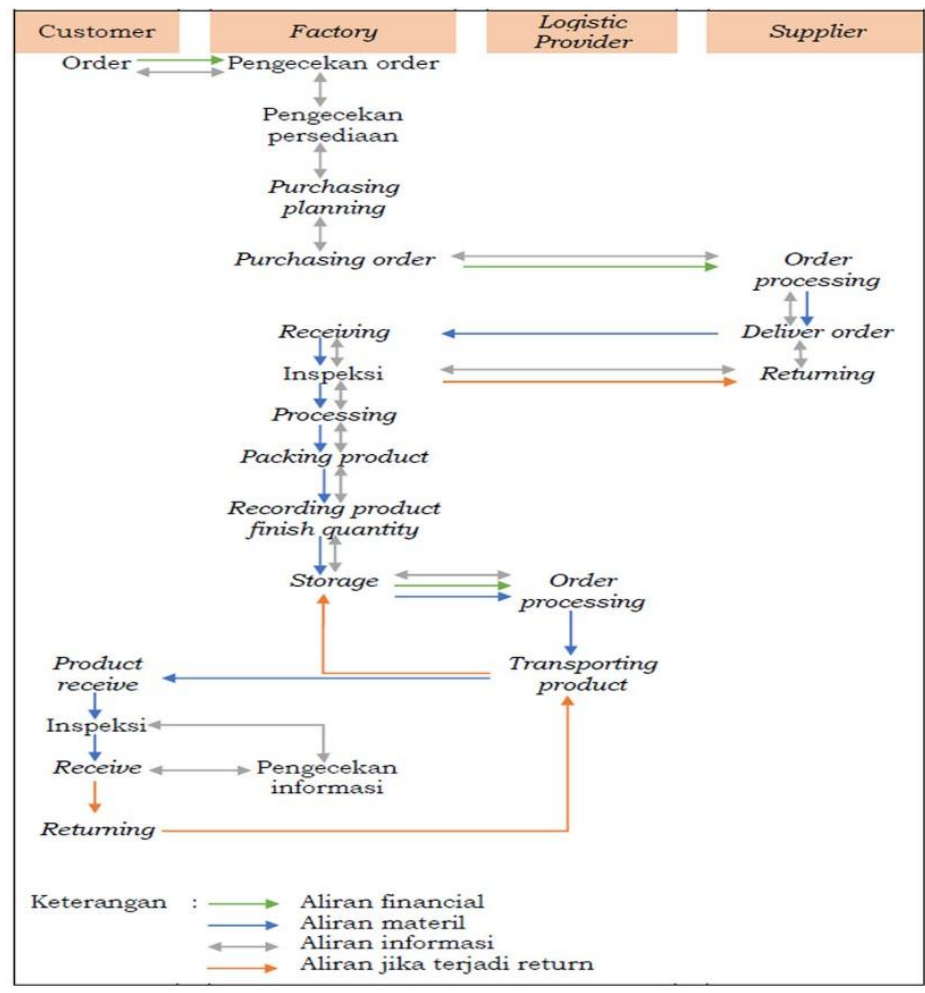

Gambar 1. Peta Aktivitas Supply Chain PT. Perikanan Nusantara (Persero) Cabang Benoa Bali 
Setelah aktivitas supply chain dijabarkan, aktivitas supply chain tersebut dikelompokkan menggunakan model SCOR dengan tujuan untuk memudahkan pemetaan aktivitas risiko.
Pemetaan aktivitas supply chain PT. Perikanan Nusantara menggunakan model SCOR didasarkan pada teori milik Pujawan (2017). Pemetaan tersebut dapat dilihat pada Tabel 1.

Tabel 1. Pemetaan Aktivitas Supply Chain PT. Perikanan Nusantara (Persero) Cabang Benoa Bali Berdasarkan Model SCOR

\begin{tabular}{|c|c|c|}
\hline SCOR & Activity & Detail Activity \\
\hline \multirow[t]{3}{*}{ Plan } & Penerimaan jumlah order & $\begin{array}{l}\text { a. Pengecekan order } \\
\text { b. Pengumpulan dan perhitungan } \\
\text { order dari customer }\end{array}$ \\
\hline & $\begin{array}{l}\text { Perhitungan dan perencanaan } \\
\text { persediaan }\end{array}$ & $\begin{array}{l}\text { a. Pengecekan stok bahan baku } \\
\text { b. Perencanaan order bahan baku } \\
\text { persediaan kepada pemasok } \\
\text { c. Penentuan pemasok }\end{array}$ \\
\hline & Perencanaan produksi & $\begin{array}{l}\text { a. Perencanaan jumlah produksi } \\
\text { b. Perencanaan waktu selesai } \\
\text { c. Pengajuan perencanaan } \\
\text { pembelian bahan baku kepada } \\
\text { divisi marketing }\end{array}$ \\
\hline \multirow[t]{3}{*}{ Source } & Komunikasi dengan pemasok & $\begin{array}{l}\text { a. Pemesanan bahan baku } \\
\text { b. Negoisasi dengan pemasok } \\
\text { c. Kontrak dengan pemasok }\end{array}$ \\
\hline & $\begin{array}{l}\text { Pengeluaran purchase order ke } \\
\text { pemasok }\end{array}$ & $\begin{array}{l}\text { a. Melakukan pembayaran } \\
\text { b. Pemasok mengirimkan material }\end{array}$ \\
\hline & Penerimaan bahan baku & $\begin{array}{l}\text { a. Melakukan inspeksi material } \\
\text { yang datang }\end{array}$ \\
\hline \multirow[t]{3}{*}{ Make } & Pelaksanaan produksi & $\begin{array}{l}\text { a. Mempersiapkan sarana/alat } \\
\text { produksi } \\
\text { b. Pelaksanaan kegiatan produksi } \\
\text { c. Inspeksi kualitas finish product }\end{array}$ \\
\hline & Packing produk & $\begin{array}{l}\text { a. Pengemasan produk } \\
\text { b. Pemberian label } \\
\text { c. Melakukan tally sheet produk } \\
\text { jadi }\end{array}$ \\
\hline & $\begin{array}{l}\text { Penyimpanan produk di cold } \\
\text { storage }\end{array}$ & $\begin{array}{l}\text { a. Melakukan pemindahan produk } \\
\text { jadi ke cold storage } \\
\text { b. Pengaturan penataan tumpukan } \\
\text { produk di cold storage }\end{array}$ \\
\hline \multirow[t]{2}{*}{ Deliver } & $\begin{array}{l}\text { Penyiapan pencatatan } \\
\text { dokumen }\end{array}$ & $\begin{array}{l}\text { a. Melakukan tally sheet produk } \\
\text { yang keluar } \\
\text { b. Mengeluarkan surat jalan atau } \\
\text { dokumen perijinan pengiriman }\end{array}$ \\
\hline & $\begin{array}{l}\text { Pengiriman produk ke } \\
\text { customer }\end{array}$ & $\begin{array}{l}\text { a. Pemilihan transportasi } \\
\text { b. Pengiriman produk ke customer }\end{array}$ \\
\hline
\end{tabular}




\begin{tabular}{|c|c|c|}
\hline \multirow[t]{2}{*}{ Return } & $\begin{array}{l}\text { Pengembalian bahan baku ke } \\
\text { pemasok }\end{array}$ & $\begin{array}{l}\text { a. Dokumentasi foto dan } \\
\text { keterangan return } \\
\text { b. Mengelurkan berita acara dan } \\
\text { surat jalan } \\
\text { c. Pengembalian produk yang rusak }\end{array}$ \\
\hline & $\begin{array}{l}\text { Pengembalian produk dari } \\
\text { customer }\end{array}$ & $\begin{array}{l}\text { a. Dokumentasi foto dan } \\
\text { keterangan return } \\
\text { b. Menerima dan inspeksi produk } \\
\text { yang di return } \\
\text { c. Mengeluarkan berita acara }\end{array}$ \\
\hline
\end{tabular}

Sumber: Data Primer (diolah), 2018

Berdasarkan Tabel 1 dapat dilihat aktivitas perusahaan yang telah dikelompokkan berdasarkan model SCOR yaitu plan, source, make, deliver, dan return. Aktivitas yang pertama yaitu plan terdapat beberapa kegiatan diantaranya penerimaan jumlah order, perencanaan persediaan, dan perencanaan produksi. Penerimaan jumlah order meliputi pengecekan dan pengumpulan jumlah produk yang di order dari customer. Perencanaan persediaan meliputi pengecekan stok dan kemudian merencanakan order kepada pemasok yang dipilih atau ditentukan. Perencanaan produksi berhubungan dengan aktivitas make, dimana perencanaan produksi disesuaikan terhadap jumlah permintaan yang masuk pada perusahaan. Permintaan tersebut sangat menentukan berapa jumlah yang akan diproduksi dan kapan waktu produksi harus selesai.

Aktivitas yang kedua yaitu source menjabarkan langkah-langkah dengan lebih detail mulai dari kontak dengan pemasok, hingga penerimaan ikan oleh perusahaan. Kegiatan aktivitas source ini diawali oleh komunikasi dengan pemasok. Komunikasi dengan pemasok ini biasa dilakukan dengan telepon maupun tatap langsung antara perusahaan dengan pemasok. Melalui komunikasi dilakukan negoisasi dengan pemasok hingga ditemui kesepakatan dan dibuat kontrak untuk purchasing order. Setelah terbuatnya kontrak, dilakukan purchase order ke pemasok yang kemudian pemasok tersebut mengirimkan bahan baku sesuai dengan kebutuhan perusahaan.

Aktivitas yang ketiga yaitu make, kegiatan-kegiatan yang termasuk dalam aktivitas ini adalah pelaksanaan kegiatan produksi. Setelah pelaksanaan kegiatan produksi, finish produk di inspeksi secara sampling dan jika lolos inspeksi produk di packing. Produk yang telah di packing tersebut disimpan di cold storage yang dimiliki perusahaan.

Aktivitas yang keempat adalah deliver, dalam aktivitas ini terdapat dua kegiatan yaitu penyiapan pencatatan dokumen dan pengiriman produk ke customer. Penyiapan pencatatan dokumen berkaitan dengan data quantity produk yang keluar, sedangkan pengiriman produk ke customer berkaitan dengan pemilihan transportasi yang akan digunakan untuk mengirimkan produk ke lokasi customer.

Pengelompokan aktivitas yang kelima adalah return, pada aktivitas ini terdapat dua kegiatan yaitu pengembalian bahan baku ke pemasok dan pengembalian produk dari customer. Pengembalian bahan baku ke pemasok dilakukan oleh perusahaan https://doi.org/10.24843/SOCA.2018.v12.i02.p04 
jika dalam incoming inspection yang dilakukan saat penerimaan bahan baku terjadi reject, sedangkan pengembalian produk dari customer dilakukan jika terjadi reject pada inspeksi quality control yang dilakukan saat diterima oleh customer. Setelah melakukan pemetaan aktivitas supply chain dengan model SCOR, tahap selanjutnya yaitu identifikasi risiko. Risiko yang diidentifikasi yaitu risk event dan risk agent, dimana risiko tersebut dianggap dapat menghambat aktivitas supply chain perusahaan.

\section{Identifikasi Risiko}

Risiko yang diidentifikasi yaitu risk event dan risk agent. Identifikasi risiko didasarkan pada hasil wawancara dan brainstorming serta data historis perusahaan. Tabel 2 berikut adalah hasil risk event yang telah teridentifikasi.

Tabel 2 Hasil Identifikasi Risk Event di PT. Perikanan Nusantara (Persero) Cabang Benoa Bali

\begin{tabular}{cl}
\hline Ei) & \multicolumn{1}{c}{ Risk Event/Kejadian Risiko } \\
\hline E1 & Kesalahan menerima spesifikasi yang dibutuhkan customer \\
E2 & Penentuan jumlah order tidak tepat \\
E3 & Stok bahan baku habis \\
E4 & Stok data tidak sesuai dengan stok fisik \\
E5 & Ketidakpastian order dari customer \\
E6 & Harga bahan baku tinggi \\
E7 & Pembelian bahan baku tidak segera diproses \\
E8 & Terlalu banyak melakukan pembelian bahan baku \\
E9 & Kesalahan inspeksi saat proses receiving incoming material \\
E10 & Ikan yang datang dari pemasok kualitasnya tidak sesuai dengan \\
& kebutuhan perusahaan \\
E11 & Perbedaan berat ikan \\
E12 & Penundaan proses produksi \\
E13 & Produksi tidak tepat waktu \\
E14 & Kesalahan proses produksi \\
E15 & Kesalahan pemberian label \\
E16 & Penumpukan produk jadi \\
E17 & Produk rusak di cold storage \\
E18 & Kesalahan dalam pencatatan dokumen pengiriman \\
E19 & Pengiriman barang terlambat untuk customer \\
E20 & Bahan baku rusak (return ke pemasok) \\
E21 & Produk rusak (return dari customer)
\end{tabular}

Sumber: Hasil Wawancara, 2018

Risk event merupakan risikorisiko yang terjadi pada perusahaan. Berdasarkan hasil identifikasi diketahui bahwa terdapat 21 risk event. Setelah identifikasi risk event, selanjutnya yaitu identifikasi risk agent yang dapat dilihat pada Tabel 3 berikut. 
Tabel 3. Hasil Identifikasi Risk Agent di PT. Perikanan Nusantara (Persero) Cabang Benoa Bali

\begin{tabular}{|c|c|}
\hline (Ai) & Risk Agent/Penyebab \\
\hline A1 & Sistem komunikasi internal perusahaan yang kurang baik/kondusif \\
\hline A2 & Kesalahan pengiriman data order \\
\hline A3 & Penambahan jumlah order dadakan \\
\hline A4 & Perubahan order dari customer \\
\hline A5 & Terdapat bahan baku yang rusak \\
\hline A6 & Kesalahan perhitungan jumlah bahan baku \\
\hline A7 & Karyawan kurang teliti menghitung stok/persediaan \\
\hline A8 & $\begin{array}{l}\text { Keteledoran karyawan dalam penginputan database produksi maupun } \\
\text { penjualan }\end{array}$ \\
\hline A9 & Pencatatan persediaan tidak langsung di input dalam database \\
\hline A10 & Jumlah order berubah-ubah atau tidak pasti \\
\hline A1 1 & Harga bahan baku yang fluktuatif \\
\hline A12 & Sistem internal (birokrasi) perusahaan yang lama/panjang prosesnya \\
\hline A13 & Menuggu persetujuan Direksi/Branch Manager \\
\hline A14 & Kesalahan perhitungan perencanaan \\
\hline A15 & Sistem informasi internal perusahaan berjalan kurang baik \\
\hline A16 & Kelalaian quality control \\
\hline A17 & Kesalahan perhitungan tally sheet \\
\hline A18 & Kurangnya quality control dari pemasok \\
\hline A19 & Proses pengiriman dilakukan secara kasar \\
\hline A20 & Terjadi bencana pada lokasi pemasok \\
\hline A2 1 & Penyusutan ikan \\
\hline A22 & Keterlambatan datangnya ikan dari pemasok \\
\hline A23 & Kebudayaan karyawan yang berbeda \\
\hline A24 & Sumberdaya manusia pada bagian produksi terbatas \\
\hline A25 & Penambahan penerimaan jumlah order dari customer \\
\hline A26 & Kelalaian karyawan \\
\hline A27 & Kesalahan handling \\
\hline A28 & Tidak mematuhi SOP \\
\hline A29 & Alat yang digunakan terbatas/tidak memadai \\
\hline A30 & Kurang teliti saat quality inspeksi \\
\hline A31 & Kesalahan dalam penyortiran \\
\hline A32 & Pekerja ahli yang terbatas \\
\hline A33 & Alokasi jumlah sumberdaya manusia kurang tepat \\
\hline A34 & Kelalaian pekerja \\
\hline A35 & Kesalahan pemberian label berdasarkan size \\
\hline A36 & Cold storage terbatas \\
\hline A37 & Kesalahan handling penataan \\
\hline A38 & Mesin pendingin tidak berfungsi saat listrik mati \\
\hline A39 & Kekeliruan perhitungan tallysheet \\
\hline A40 & Human error \\
\hline A4 1 & Kelalaian karyawan \\
\hline A42 & Perayaan hari besar \\
\hline A43 & Alat transportasi tidak memadai \\
\hline A44 & Perjalanan macet \\
\hline A45 & Hujan/bencana alam \\
\hline
\end{tabular}


A46 Kualitas tidak sesuai dengan standar yang dibutuhkan perusahaan

A47 Terjadi bencana alam pada lokasi pemasok

A48 Kualitas tidak sesuai dengan yang dipesan

A49 Kesalahan pada proses produksi

A50 Kesalahan pada proses packing

A51 Rusaknya mesin pendingin pada kontainer saat pengiriman

Sumber: Hasil Wawancara, 2018

Risk agent pada Tabel 3 Penilaian risiko dilakukan dengan merupakan penyebab dari risk event. Berdasarkan hasil identifikasi diketahui bahwa terdapat 51 risk agent.

\section{Penilaian Risiko di PT. Perikanan Nusantara (Persero) Cabang Benoa Bali} membuat perangkingan nilai Risk Priorty Number (RPN) dan menentukan level risiko. Tabel 4 berikut adalah hasil rekapitulasi akumulasi nilai RPN dari nilai yang tertinggi.

Tabel 4. Hasil Akumulasi Nilai RPN di PT. Perikanan Nusantara (Persero) Cabang Benoa Bali

\begin{tabular}{cclc}
\hline No. & (Ai) & \multicolumn{1}{c}{ Risk Agent } & RPN \\
\hline 1 & A12 & Sistem internal (birokrasi) perusahaan yang lama/panjang & 441 \\
& & prosesnya & 384 \\
2 & A26 & Kelalaian karyawan & 343 \\
3 & A4 & Perubahan order dari customer & 294 \\
4 & A3 & Penambahan jumlah order dadakan & 224 \\
5 & A20 & Terjadi bencana pada lokasi pemasok & 180 \\
6 & A40 & Human error & 140 \\
7 & A10 & Jumlah order berubah-ubah atau tidak pasti \\
8 & A33 & Alokasi jumlah sumberdaya manusia kurang tepat & 140 \\
9 & A11 & Harga bahan baku tinggi & 126 \\
10 & A13 & Menuggu persetujuan Direksi/Branch Manager & 126 \\
11 & A21 & Penyusutan ikan & 126 \\
12 & A27 & Kesalahan handling & 112 \\
13 & A29 & Alat yang digunakan terbatas / tidak memadai & 112 \\
14 & A32 & Pekerja ahli yang terbatas & 112 \\
15 & A35 & Kesalahan pemberian label berdasarkan size & 105 \\
16 & A14 & Kesalahan perhitungan perencanaan & 100 \\
17 & A19 & Proses pengiriman dilakukan secara kasar & 96 \\
18 & A28 & Tidak mematuhi SOP & 96 \\
19 & A37 & Kesalahan handling penataan & 96 \\
20 & A16 & Kelalaian quality control & 90 \\
21 & A25 & Penambahan penerimaan jumlah order dari customer & 90 \\
22 & A18 & Kurangnya quality control dari pemasok \\
23 & A24 & Sumberdaya manusia pada bagian produksi terbatas & 84 \\
24 & A31 & Kesalahan dalam penyortiran & 81 \\
25 & A5 & Terdapat bahan baku yang rusak & 80 \\
26 & A41 & Kelalaian karyawan & 72 \\
27 & A30 & Kurang teliti saat quality inspeksi & 63 \\
28 & A44 & Perjalanan macet
\end{tabular}


29 A6 Kesalahan perhitungan jumlah bahan baku 56

30 A8 Keteledoran karyawan dalam penginputan database 50 produksi maupun penjualan

31 A9 Pencatatan persediaan tidak langsung di input dalam 50 database

32 A45 Hujan/bencana alam 45

33 A34 Kelalaian pekerja 42

34 A49 Kesalahan pada proses produksi 42

35 A15 Sistem informasi internal perusahaan berjalan kurang baik 40

36 A22 Keterlambatan datangnya ikan dari pemasok 40

37 A17 Kesalahan perhitungan tally sheet 36

38 A2 Kesalahan pengiriman data order 35

39 A36 Cold storage terbatas 35

40 A48 Kualitas tidak sesuai dengan yang dipesan 35

41 A7 Karyawan kurang teliti menghitung stok/persediaan 32

42 A42 Perayaan hari besar 30

43 A50 Kesalahan pada proses packing 28

44 A51 Rusaknya mesin pendingin pada kontainer saat 28

45 A39 $\begin{aligned} & \text { pengiriman } \\ & \text { kekeliruan perhitungan tallysheet }\end{aligned}$

46 A23 Kebudayaan karyawan yang berbeda 15

$\begin{array}{llll}47 & \text { A43 Alat transportasi tidak memadai } & 15\end{array}$

48 A46 Kualitas tidak sesuai dengan standar yang dibutuhkan $\quad 14$

49 A1 Sistem komunikasi internal perusahaan yang kurang 10

$\begin{array}{llll}50 & \text { A47 } & \text { baik/kondusif } & \\ \text { Terjadi bencana alam pada lokasi pemasok } & 10\end{array}$

51 A38 Mesin pendingin tidak berfungsi saat listrik mati 8

Sumber: Hasil Analisis Penelitian, 2018

Berdasarkan Tabel 4 diketahui penyebabnya. Nilai RPN terendah yaitu bahwa nilai RPN tertinggi yaitu $441 \quad 8$ pada (E17) produk rusak di cold pada kejadian (E7) pembelian bahan storage dengan (A38) mesin pendigin baku tidak segera diproses dengan (A12) tidak berfungsi saat listrik mati sebagai sistem internal (birokrasi) perusahaan penyebabnya. Gambar 2 Berikut adalah yang lama/panjang prosesnya sebagai hasil pemetaan level risiko. 


\begin{tabular}{|c|c|c|c|c|}
\hline \multirow{2}{*}{\multicolumn{2}{|c|}{ Risk Level }} & \multicolumn{3}{|c|}{ RPN } \\
\hline & & $1-71$ & $72-391$ & $392-1000$ \\
\hline \multirow{3}{*}{ 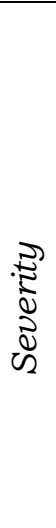 } & $1-6$ & $\begin{array}{c}\text { A44, A6, A8, A9, } \\
\text { A45, A15, A17, A7, } \\
\text { A42, A39, A23, } \\
\text { A43, A46, A1, A47 }\end{array}$ & $\begin{array}{c}\text { A20, A40, A10, } \\
\text { A11, A14, A19, } \\
\text { A16, A25, A18, } \\
\text { A24, A5, A41, A22 }\end{array}$ & \\
\hline & $7-8$ & $\begin{array}{c}\text { A30, A34, A49, A2, } \\
\text { A36, A48, A50 } \\
\text { A51, A38 }\end{array}$ & $\begin{array}{l}\text { A26, A4, A3, A33, } \\
\text { A13, A21, A27, } \\
\text { A29, A32, A35, } \\
\text { A28, A37, A31 }\end{array}$ & A12 \\
\hline & $9-10$ & & & \\
\hline
\end{tabular}

Gambar 2. Peta level risiko FMEA di PT. Perikanan Nusantara (Persero) Cabang Benoa Bali

Berdasarkan peta tersebut prioritas fokus dalam proses diketahui terdapat 37 agen risiko pada area hijau yaitu kategori Broadly Acceptable (BA), 13 risiko pada area kuning yaitu kategori As Low As is Reasonably Practicable (ALARP), dan 1 risiko pada area merah yaitu kategori Intoreable (INT). Risiko yang memerlukan aksi mitigasi adalah risiko yang berada pada kategori ALARP, karena dianggap dapat mengganggu atau menghambat kinerja supply chain perusahaan. Risiko inilah yang menjadi

perencanaan mitigasi risiko.

\section{Perencanaan Mitigasi Risiko di PT. Perikanan Nusantara (Persero) Cabang Benoa Bali}

Tabel 5 berikut adalah beberapa perencanaan upaya mitigasi risiko yang telah dirumuskan peneliti dan telah ditanggapi oleh supervisior di PT. Perikanan Nusantara (Persero) Cabang Benoa Bali. Supervisior tersebut bertanggung jawab untuk meminimalisir risiko yang mungkin terjadi.

Tabel 5. Perencanaan Upaya Mitigasi Risiko di PT. Perikanan Nusantara (Persero) Cabang Benoa Bali

\begin{tabular}{clcl}
\hline No & \multicolumn{1}{c}{ Mitigasi } & (Ai) & \multicolumn{1}{c}{ Risk Agent } \\
\hline 1 & Pelatihan kedisiplinan dalam & A26 & Kelalaian karyawan \\
& bekerja, top manager lebih ketat & A27 & Kesalahan handling \\
& monitoring pekerjaan, dan & A35 & Kesalahan pemberian label \\
& memberikan reward and & & berdasarkan size \\
punishment. & A28 & Tidak mematuhi SOP \\
& & A37 & Kesalahan handling penataan \\
& Meloby atau membujuk customer & A4 & Perubahan order dari customer \\
& lain untuk membeli ikan lebih & &
\end{tabular}


banyak, memberikan penalty, dan memperjelas tentang perubahan order pada perjanjian PO

3 Melakukan analisa min max stock

$4 \quad$ Evaluasi ulang perencanaan sumberdaya manusia

5 Meeting pengusulan alur prosedur terbaik

6 Menyamakan timbangan dan memperkecil toleransi penyusutan

7 Memperhitungkan penambahan aset

8 Perekrutan sumberdaya manusia baru dan pelatihan terhadap karyawan baru
A3 Penambahan jumlah order dadakan

A33 Alokasi sumberdaya manusia kurang tepat

A13 Menunggu persetujuan Direksi/ Branch Manager

A2 1 Penyusutan ikan

A29 Alat yang digunakan terbatas/tidak memadai

A32 Pekerja ahli yang terbatas

Sumber: Hasil Perencanaan Mitigasi oleh Peneliti dan Supervisior di PT. Perikanan Nusantara (Persero) Cabang Benoa Bali, 2018

Berdasarkan Tabel 5 dapat dilihat terdapat delapan perencanaan upaya mitigasi risiko. Keseluruhan upaya mitigasi dijelaskan lebih lanjut sebagai berikut.

1. Perencanaan mitigasi yang pertama dilakukan dengan mitigate risk yaitu mengurangi peluang dan dampak risiko yang terjadi. Mitigasi yang dilakukan adalah memberikan atau mengadakan pelatihan penanaman kedisiplinan dalam bekerja. Melalui program tersebut karyawan ada peningkatan rasa bertanggung jawab terhadap pekerjaan, dan pihak top management harus lebih ketat dalam memonitoring pekerjaan. Selain itu perlu dilakukan penilaian kinerja dengan memberikan reward dan punishment. Adanya penilaian kinerja akan dapat diketahui sampai mana kinerja dari karyawan. Karyawan yang berprestasi diberikan reward sehingga karyawan tersebut termotivasi untuk mempertahankan dan meningkatkan prestasi tersebut, sedangkan karyawan yang menunjukkan buruk kinerjanya diberikan punishment sehingga karyawan tersebut termotivasi untuk meningkatkan kinerjanya. Perencanaan mitigasi ini adalah untuk menangani enam agen risiko yang disebabkan oleh kesalahan tenaga kerja yaitu (A26) kelalaian karyawan, (A27) kesalahan handling, (A35) kesalahan pemberian label berdasarkan size, (A28) tidak mematuhi SOP, (A37) kesalahan handling penataan, dan (A31) kesalahan dalam penyortiran. Risiko yang disebabkan oleh kesalahan tenaga kerja merupakan faktor terbanyak yang menghambat kelancaran supply chain perusahaan.

2. Mitigasi risiko yang kedua dilakukan dengan transfer risk 
yaitu memindahkan atau membagi risiko dengan pihak lain. Apabila terdapat produk yang menumpuk maka secepatnya pihak marketing harus segera meloby atau membujuk customer lain untuk melakukan pembelian ikan lebih banyak. Melalui perlakuan tersebut maka produk tidak menumpuk terlalu lama dan tidak menurunkan penjualan. Selain itu, apabila perubahan order dikurangi secara signifikan pihak PT. Perikanan Nusantara (Persero) Cabang Benoa Bali dapat memberikan penalty dengan mengurangi jumlah order customer tersebut pada order selanjutnya. Penanganan yang lebih penting lagi adalah memperjelas tentang perubahan order pada perjanjian PO yang telah disepakati sebelumnya. Mitigasi ini dilakukan untuk menangani risk agent (A4) perubahan order dari customer. Perubahan order dari customer merupakan risiko yang beberapa kali mengakibatkan penumpukan produk di coldstorage.

3. Mitigasi risiko yang ketiga adalah menentukan atau melakukan analisa min max stock. Tujuannya adalah agar perusahaan tidak mengalami kekurangan maupun kelebihan stok. Kekurangan stok dapat mengakibatkan terhambatnya produksi dan tidak dapat memenuhi permintaan customer, sedangkan kelebihan stok dapat menimbulkan pemborosan karena perusahaan mengeluarkan modal lebih besar untuk biaya stok. Penanganan dengan min max stock akan menghasilkan hasil yang lebih efisien. Mitigasi ini dilakukan untuk menangani risk agent (A3) penambahan jumlah order dadakan. Penambahan jumlah order dadakan pada saat telah melakukan purchase order kepada pemasok merupakan risiko yang beberapa kali membuat perusahaan tidak dapat memenuhi kebutuhan atau permintaan customer.

4. Mitigasi risiko yang ke empat adalah melakukan evaluasi ulang perencanaan sumberdaya manusia. Perencanaan tersebut dilakukan dengan menentukan atau melihat potensi masingmasing karyawan. Apabila karyawan tidak dapat memenuhi bagian atau tugasnya maka perlu dilakukan reshuffle posisi. Hal tersebut dilakukan untuk memastikan bahwa jumlah dan kualitas dengan ketrampilan yang dibutuhkan sudah tepat. Mitigasi ini dilakukan untuk menangani risk agent (A33) alokasi jumlah sumberdaya manusia kurang tepat. Alokasi jumlah sumberdaya manusia kurang tepat merupakan salah satu risiko yang berpengaruh dalam mencapai tujuan dan kemajuan perusahaan.

5. Menunggu persetujuan direksi/branch manager merupakan risiko yang beberapa kali menyebabkan perusahaan kehilangan customer. Customer membatalkan pembelian karena menunggu kepastian lama. Mitigasi yang kelima adalah pihak PT. Perikanan Nusantara (Persero) Cabang Benoa Bali adalah melakukan meeting untuk mengusulkan alur prosedur yang terbaik. Salah satunya adalah meeting persetujuan untuk memberikan wewenang 
kepercayaan pada bagian pembelian atau marketing. Tujuannya adalah untuk mempertahankan customer sehingga pihak perusahaan tidak kehilangan probabilitas keuntungan. Mitigasi risiko ini dilakukan untuk menangani risk agent (A13) menunggu persetujuan direksi/branch manager. Risiko tersebut merupakan risiko yang beberapa kali menyebabkan perusahaan kehilangan customer. Customer membatalkan pembelian karena lama menunggu kepastian.

6. Mitigasi risiko yang keenam adalah menangani dengan cara pihak perusahaan menyediakan timbangan di dermaga agar timbangan yang digunakan sama yaitu timbangan digital, karena berdasarkan observasi yang telah dilakukan sebelumnya pihak nelayan di dermaga menggunakan timbangan gantung sedangkan pihak perusahaan menggunakan timbangan digital. Selain itu hal yang dapat dilakukan untuk menangani risiko ini adalah dengan memperkecil presentase toleransi penyusutan untuk mengurangi kerugian. Perlu dilakukan meneliti per ikan seberapa besar penyusutannya untuk mempermudah dalam menentukan presentase toleransinya dan mengurangi kesempatan berbuat curang. Mitigasi risiko ini dilakukan untuk menangani risk agent (A21) penyusutan ikan. Risiko tersebut merupakan risiko yang cukup berpengaruh dalam laba-rugi yang ditanggung PT. Perikanan Nusantara (Persero) Cabang Benoa Bali.
7. Mitigasi yang ketujuh dapat dilakukan dengan memperhitungkan penambahan aset. Aset merupakan hal yang sangat penting dalam pencapaian hasil output yang tinggi atau sesuai dengan tujuan, dengan penambahan aset perusahaan dapat menghasilkan laba maksimum. Mitigasi ini dilakukan untuk menangani risk agent (A29) alat yang digunakan terbatas/tidak memadai. Risiko tersebut dikarenakan kurang memadainya fasilitas produksi yang ada di perusahaan. Risiko ini harus secepatnya diberikan mitigasi karena apabila dibiarkan maka risiko ini akan muncul secara terus menerus.

8. Mitigasi risiko yang terakhir adalah melakukan perekrutan sumberdaya manusia baru dengan memberlakukan masa magang. Selain itu juga mengadakan pelatihan terhadap karyawankaryawan baru. Tujuan dari perlakuan tersebut adalah untuk memastikan bahwa karyawan dapat melakukan pekerjaan yang membutuhkan keahlian. Hal tersebut memang membutuhkan waktu dan biaya lebih, namun merupakan investasi yang memiliki nilai tinggi untuk perusahaan. Mitigasi ini dilakukan untuk menangani risk agent (A32) pekerja ahli yang terbatas. Pekerja ahli yang terbatas di PT. Perikanan Nusantara (Persero) Cabang Benoa Bali merupakan salah satu risiko penyebab terhambatnya kelancaran proses produksi. 


\section{PENUTUP}

\section{Kesimpulan}

Berdasarkan hasil analisis dan pembahasan maka disimpulkan sebagai berikut.

1. Terdapat 21 risk event dan 51 risk agent di PT. Perikanan Nusantara (Persero) Cabang Benoa Bali yang tersebar pada akitivitas plan, source, make, deliver, dan return.

2. Risiko yang tertinggi masuk pada kategori Intolerable dengan nilai RPN tertinggi yaitu 441, dan risiko yang terendah masuk pada kategori Broadly Acceptable dengan nilai RPN terendah yaitu 8 .

3. Terdapat delapan rencana mitigasi untuk meminimalisir risiko di PT. Perikanan Nusantara (Persero) Cabang Benoa Bali yaitu: (1) Pelatihan kedisiplinan dalam bekerja, top manager lebih ketat monitoring pekerjaan, dan memberikan reward and punishment, (2) Meloby customer lain untuk membeli ikan lebih banyak, memberikan pinalty, dan memperjelas tentang $\mathrm{PO}, \quad$ (3) Melakukan analisa min max stock, (4) Evaluasi ulang perencanaan sumberdaya manusia, (5) Meeting pengusulan alur prosedur terbaik, (6) Menyamakan timbangan dan memperkecil toleransi penyusutan, (7) Memperhitungkan penambahan aset, (8) Perekrutan sumberdaya manusia baru dan pelatihan terhadap karyawan baru.

\section{Saran}

Berdasarkan hasil penelitian dan kesimpulan, maka saran-saran yang dapat diberikan berkaitan dengan PT. Perikanan Nusantara (Persero) Cabang Benoa Bali adalah sebagai berikut.
1. Risiko yang timbul dalam aktivitas supply chain perusahaan dapat menjadi risiko yang berdampak besar jika tidak mendapat perhatian dalam proses pengelolaan risiko supply chain perusahaan. Maka dari itu, perlu perhatian khusus dalam menetapkan risk event dan risk agent. Penetapan disesuaikan dengan definisi dari risiko yang diacu, sehingga tidak terjadi kekeliruan dalam penilaian risiko selanjutnya.

2. Perusahaan perlu melakukan penilaian risiko secara berkala dan berkelanjutan agar dapat melakukan mitigasi untuk meminimalisir kerugian jika terjadi risiko yang berakibat negatif pada perusahaan.

3. Mitigasi risiko harus secepatnya ditindaklanjuti agar risiko yang ada tidak muncul secara terus menerus.

4. Peneliti selanjutnya diharapkan dapat melakukan kajian risiko supply chain secara menyeluruh mulai dari sudut pandang supplier hingga sudut pandang customer atau konsumen akhir, karena pada penelitian ini yang dikaji hanya risiko supply chain dari sisi internal perusahaan saja.

\section{UCAPAN TERIMAKASIH}

Ucapan terimakasih penulis tujukan kepada para informan penelitian, keluarga, teman-teman, serta semua pihak yang telah membantu dalam penelitian ini.

\section{DAFTAR PUSTAKA}

AS/NZS 4360. 2004. Australian/New Zealand Standard Risk Management. Strathfield: 
Standards Australia/Standards New Zealand

Christopher, M. 2011. Logistic \& Supply Chain Management. Pearson Education

Moleong, L. J. 2009. Metode Penelitian Kualitatif. Bandung: PT. Remaja Rosdakarya

PT. Perikanan Nusantara. 2017. Laporan Kondisi SDM, Umum, dan Logistik Tahun 2017. PT. Perikanan Nusantara (Persero) Cabang Benoa. Bali

PT. Perikanan Nusantara. 2017. Laporan Operasional Semester I Tahun 2017. PT. Perikanan Nusantara (Persero) Cabang Benoa. Bali

PT. Perikanan Nusantara. 2017. Laporan Operasional Semester II Tahun 2017. PT. Perikanan
Nusantara (Persero) Cabang Benoa. Bali

Pujawan, I. N., dan Erawati, M. 2017. Supply Chain Management. Yogyakarta: ANDI

Pujawan, I. N.., Geraldin, L. H., dan Dewi, D. S. 2007. Management Risiko dan Aksi Mitigasi untuk Menciptakan Rantai Pasok yang Robust. Jurnal Teknologi dan Rekayasa Teknik Sipil "TORST", pp. 53-63

Sanjoyo, Y., dan Lestari, Y., D. 2016. Analisis dan Mitigasi Risiko Supply Chain pada CV. Apaiser. Manajemen, Universitas Airlangga: Surabaya

Zaroni. 2015. Manajemen Risiko Rantai Pasok dalam Model SCOR. Senior Consultant Supply Chain Indonesia: Supply Chain Indonesia. 